\title{
Occupational asthma due to EPO 60
}

\author{
E M Lambourn, J P Hayes, W A C McAllister, A J Newman Taylor
}

We report a case of asthma caused by exposure at work to EPO 60, an epoxy resin hardening agent. Inhalation tests with the hardening agent and resin reproducibly provoked an isolated late asthmatic response without change in airway responsiveness to inhaled histamine.

\section{Case report}

A 44 year old mould maker and fitter who had worked in the same job for six years presented with a two year history of chest tightness. He made wooden model components to which strips of carbon fibre were fixed by applying an epoxy resin system with its curing agent, a polyamine EPO 60 . These were then baked in an oven at $180^{\circ} \mathrm{C}$. Initially his respiratory symptoms occurred in evenings after work, but during the previous year his symptoms had deteriorated and he had developed wheezing and chest tightness on waking in the morning as well as after work in the evening. His symptoms resolved when away from work, at weekends and on holidays, and when he avoided exposure to the hardening agent at work.

He had had no important respiratory or other illnesses in the past and had no personal or family history of asthma or hay fever. He smoked one ounce of tobacco a week. When seen initially his forced expiratory volume $\left(\mathrm{FEV}_{1}\right)$ and forced vital capacity (FVC) were $3.58 \mathrm{l}$ and $4.41 \mathrm{l}$, and did not improve after inhalation of bronchodilator. He had immediate skin prick test responses elicited by extracts of house dust, house dust mite, and dog hair (Bencard).

He was admitted to hospital for inhalation tests. On separate days, in a single blind fashion, he was exposed to the epoxy resin alone and to the resin with EPO 60 by brush painting for periods of 20 minutes in a specially designed exposure chamber.

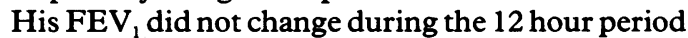
after exposure to the epoxy resin. Exposure to the mixture of EPO 60 and epoxy resin reproducibly

Department of Occupational and Environmental Medicine, Royal Brompton and National Heart and Lung Hospital, Sydney Street, London SW3 6NP E M Lambourn, J P Hayes, A J Newman Taylor Royal Surrey County Hospital, Guildford, Surrey W A C McAllister

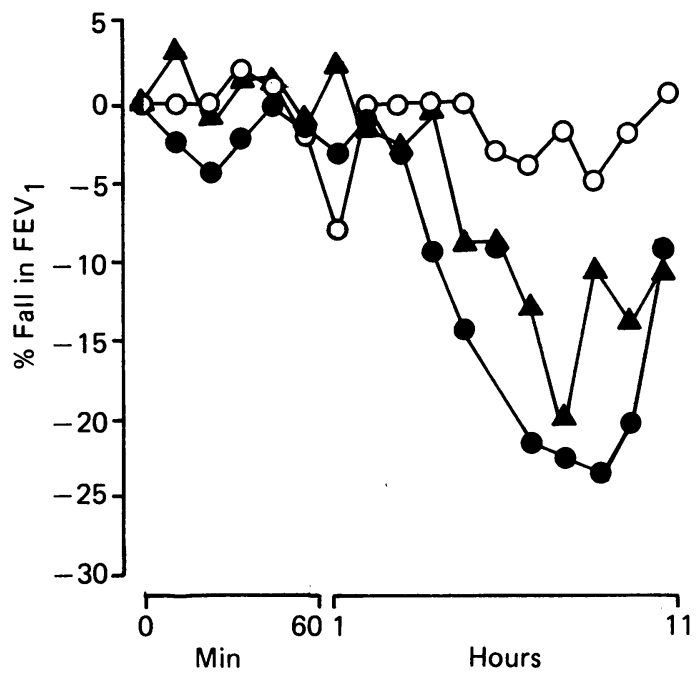

The percentage fall in $F E V_{1}$ after specific inhalation tests to a control substance ( $O$ ) and to EPO 60 on two separate occasions ( $\mathbf{\Delta}$ ).

provoked an isolated late asthmatic response with falls in $\mathrm{FEV}_{1}$ of $23 \%$ and $20 \%$ (figure). Histamine $P_{20}$ was greater than $16 \mathrm{mg} / \mathrm{ml}$ before the series of inhalation tests, and did not change when measured before and at three and 24 hours after each test. The patient was informed of the cause of his asthma; the epoxy resin system used at his workplace was changed and he has since been able to continue at work without respiratory symptoms.

\section{Discussion}

Polyamines are widely used as hardening agents for cold curing epoxy resin systems. Several different polyamines encountered at work have been reported to cause asthma ${ }^{1-3}$ although the number of cases remains small. We describe here a case of asthma caused by EPO 60, a polyamine hardening system. This contains a number of aromatic amines including; 4-4' diaminodiphenyl methane, isophorone diamine, and tetraethylene pentamine (TEPA). The heat of the curing reaction between EPO 60 and the epoxy resin generates vapour that contains several different constituents. These include TEPA. 
We were not able to identify which constituent released during curing was the cause of this patient's asthma. It is of interest, however, that TEPA is a homologue of triethylene tetramine, a previously described cause of occupational asthma. ${ }^{3}$

The absence of non-specific airway hyper-responsiveness to inhaled histamine in this patient before inhalation testing was consistent with his prolonged absence from exposure and absence of symptoms at this time. The lack of an increase associated with the provoked late asthmatic response is unusual. Durham $e t \mathrm{al}^{4}$ found that the late asthmatic response provoked by occupational agents was associated with a decrease in histamine $\mathrm{PC}_{20}$ at three and 24 hours after the inhalation test. Malo et al, ${ }^{5}$ however, subsequently described a patient in whom a late asthmatic response provoked by western red cedar dust was not associated with an increase in non-specific airway responsiveness. This suggests that the relation between late asthmatic responses and increased airway responsiveness, although usual, is not invariable.

Our patient was similar to the patient reported by Malo et $a l^{5}$ in having a late asthmatic response reproducibly provoked by the inducing cause of his asthma without an associated increase in airway responsiveness.

The underlying mechanism of induction of asthma in this patient, as with other reported cases of asthma caused by polyamines, is not known. The clinical history, absence of respiratory symptoms in others working with him, and analogy with other chemical causes of occupational asthma such as acid anhydrides, ${ }^{6}$ suggests an acquired hypersensitivity response, probably as the outcome of a specific immunological reaction.

Requests for reprints to: A J Newman Taylor, Department of Occupational and Environmental Medicine, Royal Brompton and National Heart and Lung Hospital, Sydney Street, London SW3 6NP.

1 Vallieres M, Cockcroft DW, Taylor DM, Dolovich J, Hargreave FE. Dimethylethanolamine-induced asthma. Am Rev Respir Dis 1977;115:867-71.

2 Lam S, Chan-Yeung M. Ethylenediamine-induced asthma. Am Rev Respir Dis 1980;121:151-5.

3 Fawcett IW, Newman Taylor AJ, Pepys J. Asthma due to inhaled chemical agents-epoxy resin systems containing phthalic acid anhydride, trimellitic acid anhydride and triethylene tetramine. Clinical Allergy 1977;7:1-14.

4 Durham SR, Graneek BJ, Hawkins R, Newman Taylor AJ. The temporal relationship between increases in airway responsiveness to histamine and late asthmatic responsiveness induced by occupational agents. J Allergy Clin Immunol 1987;79: 398-406.

5 Malo J-L, L'Archeveque J, Cartier A. Significant changes in nonspecific bronchial responsiveness after isolated immediate bronchospecific reactions caused by isocyanates but not after a late reaction caused by plicatic acid. J Allergy Clin Immunol 1989;83:159-65.

6 Newman Taylor AJ, Venables KM, Durham SR, Graneek BJ, Topping MD. Acid anhydrides and asthma. Int Arch Allergy Appl Immunol 1987;82:435-9.

Accepted 22 July 1991 